\title{
Centros de documentação de Boa Vista/RR: diagnóstico e problematização
}

Carla Gisele Macedo S. M. Moraes *

Paulina Onofre Ramalho **

\section{Resumo}

Este artigo apresenta as conclusões da primeira etapa da pesquisa "Diagnóstico e Cadastramento do Acervo Documental dos Centros de Informação de Boa Vista/RR", cujo objetivo é a identificação das principais dificuldades que pesquisadores e instituições enfrentam, respectivamente, para acessar, conservar e difundir a documentação histórica de Roraima. A coleta de dados através de questionário e observação in loco revelou, como resultado, o diagnóstico sobre a segurança, as condições de acondicionamento do acervo, as instalações físicas e os recursos materiais dos principais centros de documentação de Boa Vista.

Palavras-chave: Serviços de informação. Conservação de acervos. Diagnóstico de acervos.

\section{Documentation Centers of Boa Vista / RR: Diagnosis and problematization}

\begin{abstract}
This article presents the conclusions of the first stage of the research "Diagnostic and Register of the Documental Archives of the Documentation Centers of Boa Vista /RR", the objective of which is the identification of the main difficulties faced by researchers and institutions, respectively, to access, to guard and to publicize the historical documentation of Roraima. The collection of data through questionnaires and in loco observation resulted in a diagnosis about the security, the physical conditions of maintenance of the documents and of the building itself and the material resources of the most important documentation centers of Boa Vista.
\end{abstract}

Key-words: Information services. Collections conservation. Collections diagnostic. 


\section{Introdução}

O presente artigo expõe as conclusões da primeira etapa da pesquisa "Diagnóstico e Cadastramento do Acervo Documental dos Centros de Informação de Boa Vista/RR", desenvolvida no âmbito do Instituto do Patrimônio Histórico e Artístico Nacional (IPHAN), como atividade do Programa de Especialização em Patrimônio (PEP). Esta etapa consiste na identificação das principais dificuldades que pesquisadores e instituições enfrentam, respectivamente, para acessar e conservar a documentação histórica de Roraima.

Percebemos no estado de Roraima, nos últimos anos, um relativo incremento no quadro das pesquisas desenvolvidas nas mais diversas áreas. No entanto, elas continuam extremamente escassas se comparadas ao potencial do estado. Analisando essa insuficiência dos trabalhos realizados, percebemos que a grande dificuldade de se desenvolver uma pesquisa são as fontes, ou melhor, o acesso a elas.

Nesse sentido, consideramos importante um trabalho que se destine a fazer um diagnóstico do atual estado dos centros de informação de Boa Vista e das condições de acesso às fontes documentais.

Inicialmente, para embasar as questões metodológicas e o trabalho de campo, teceremos uma discussão conceitual a partir de princípios da arquivologia e biblioteconomia. Em seguida, apresentaremos a metodologia utilizada e os resultados produzidos. As considerações finais abordam o atual estado dos centros de documentação de Boa Vista e suas implicações para as pesquisas empreendidas em Roraima. Situamos nossa iniciativa, nessa conjuntura, como uma contribuição para o conhecimento, manuseio e tratamento da documentação roraimense.

\section{A gestão dos centros de documentação: conceitos e princípios}

Ao desenvolvermos a pesquisa, recorremos aos conceitos utilizados pela Arquivologia para definir, segundo a finalidade, as instituições que possuem a guarda dos documentos de Roraima: 
ARQUIVO - É a acumulação ordenada dos documentos, em sua maioria textuais, criados por uma instituição ou pessoa, no curso de sua atividade, e preservados para a consecução de seus objetivos, visando à utilidade que poderão oferecer no futuro.

BIBLIOTECA - É o conjunto de material, em sua maioria impresso, disposto ordenadamente para estudo, pesquisa e consulta.

MUSEU - É o conjunto de interesse público, criado com a finalidade de conservar, estudar e colocar à disposição do público conjuntos de peças e objetos de valor cultural.

$[\ldots]$

CENTRO DE DOCUMENTAÇÃO - Tem por finalidade coligir, armazenar, classificar, selecionar e disseminar toda a informação. (PAES, 2004, p. 16-17, grifo do autor)

A partir destes conceitos, percebemos que o centro de documentação ou informação é o mais complexo, tendo em vista que reúne documentação diversificada (livros, filmes, relatórios, microfilmes, fotografias, mapas etc.) e "abrange algumas atividades próprias da biblioteconomia, da arquivística e da informática" (PAES, 2004, p. 17). Assim, seu campo de atuação é mais amplo que o dos órgãos de documentação especializados em um único tipo de documento. Para efeito deste trabalho, o termo centro de documentação ou informação será utilizado, de maneira geral, para designar os locais pesquisados.

O estabelecimento de uma nomenclatura mais eficiente para designar os locais que guardam os documentos surgiu da ampliação do conceito de acervo que, inicialmente restrito ao documento em suporte de papel, agora inclui documentos de diferentes espécies (atas, decretos, relatórios, diapositivos, gravuras, plantas, mapas) e gêneros (audiovisuais, filmográficos, iconográficos, cartográficos, sonoros, informáticos, textuais) (PAES, 2004, p. 25-26). Esta ampliação do conceito aumentou a complexidade da gestão de acervos, exigindo novos instrumentos de conservação e segurança (MUSEU de Astronomia e Ciências Afins, 2006, p. 5).

Segundo Güths, os desafios da conservação são muitos, contribuindo para a deterioração dos acervos fatores diversos, que vão desde a ação antrópica até as condições ambientais do local em que o acervo está acondicionado (MUSEU de Astronomia e Ciências Afins, 2007, p. 27). De acordo com Carvalho, a conservação preventiva é, na atual conjuntura da gestão de acervos, uma alternativa viável e econômica: 
A conservação preventiva se aplica a todos os elementos do patrimônio em situação de deterioração ativa ou não, visando protegê-los de qualquer agressão natural e humana, e a adoção de medidas de conservação preventiva é, também, uma resposta dos profissionais que atuam no campo da preservação do patrimônio cultural às modificações de uso dos edifícios históricos, às variações dos sistemas de propriedade das coleções, às mudanças das condições ambientais do entorno, que tanto interferem no estado de conservação das coleções.

O ambiente é o campo de ação privilegiado da conservação preventiva, sendo o controle ambiental uma das suas principais estratégias. (MUSEU de Astronomia e Ciências Afins, 2007, p. 36).

Este controle parte de estratégias diferenciadas, dependentes da realidade de cada local, que incluem medidas de manutenção dos níveis de temperatura, umidade relativa, iluminação, bem como a exclusão das condições favoráveis à biodeterioração (poluição, incidência solar, fungos, mofo e cupins). Do mesmo modo, as instalações físicas do prédio que abriga o acervo requerem medidas específicas, pois, quando não são satisfatoriamente estruturadas contribuem para sua deterioração. Como ressalta Güths, "nos prédios antigos temos problemas nos sistemas elétrico e hidráulico, salas inadequadas, [falta de] segurança contra roubo, dificuldades de adaptação de um edifício para guarda de acervos" (MUSEU de Astronomia e Ciências Afins, 2007, p. 27).

As condições ideais do acervo pressupõem um ambiente seguro, prevenido contra incêndio e planejado de modo que não haja incidência de luz natural e ocorra um controle da iluminação artificial, mantendo a umidade estável (entre 45 e 58\%) e a temperatura sem grandes oscilações (entre 20 e $22^{\circ} \mathrm{C}$ ), através do uso constante de aparelhos de ar condicionado e desumidificadores (1). No caso de acervos já danificados, algumas operações de conservação podem auxiliar na recuperação dos documentos, tais como desinfestação, limpeza, alisamento e restauração ou reparo (PAES, 2004, p. 142).

Além dos problemas propriamente relacionados à conservação, é perceptível, na relação entre o público e o acervo, um distanciamento e desconhecimento da sua finalidade. Ainda reina a ideia do museu como um antiquário, local que somente 
guarda e expõe coisas antigas. A biblioteca, por sua vez, é utilizada principalmente por estudantes do ensino fundamental e médio durante suas tarefas escolares. $\mathrm{Da}$ mesma maneira, o arquivo público é encarado como o local que reúne uma documentação velha, fechada e restrita. Esta mentalidade vai de encontro ao uso social desses espaços, que guardam fragmentos da história, da memória e do saber humano e têm como compromisso a difusão do conhecimento.

A partir desta constatação, Belloto propõe "a extroversão dos arquivos, com a interação com a comunidade, tanto o público escolar, como o adulto [em] geral, tendo como usuário não apenas o pesquisador, mas o cidadão" (BELLOTO apud FUNARI, 2006, p. 130).

Já existe uma legislação que regulamenta a conservação e extroversão de acervos, estabelecendo normas e responsabilidades sobre os documentos. O Governo Federal reconhece, desde 1937 (Decreto-Lei №. 25/1937), a importância da preservação dos arquivos, sejam eles públicos ou privados. A Lei no. 8.159, de 08 de janeiro de 1991, dispõe, em seu Art. 1ํㅜ, que

É dever do Poder Público a gestão documental e a proteção especial a documentos de arquivos, como instrumento de apoio à administração, à cultura, ao desenvolvimento científico e como elementos de prova e informação. (BRASIL, 1991).

As pessoas físicas ou jurídicas que possuem arquivos relevantes para a história, a cultura e o desenvolvimento nacional de interesse público e social também estão sujeitas a normas jurídicas. $O$ artigo 9 o do Decreto $n^{\circ}$. 2.942, de 18 de janeiro de 1999 esclarece que:

Os proprietários ou detentores de arquivos privados declarados de interesse público e social devem manter preservados os acervos sob sua custódia, ficando sujeito à responsabilidade penal, civil e administrativa, na forma da legislação em vigor, aquele que desfigurar ou destruir documentos de valor permanente.

Todos esses procedimentos técnicos e legislativos constituem o respaldo a partir do qual alicerçamos o diagnóstico dos centros de informação. 


\section{Diagnóstico e problematização: a situação dos centros de documentação}

O I Encontro Roraimense dos Estudantes de História, promovido em 2008 pelos acadêmicos de História da UFRR e UERR, abordou questões fundamentais para o debate sobre os centros de documentação de Roraima. A inexistência de um arquivo público e a indisponibilidade da documentação produzida pelas instituições do estado, tanto para o público em geral como para os pesquisadores em particular, foram alguns dos aspectos discutidos no evento. Sobre o arquivo público, sabemos que:

O arquivo público [...] ainda não existe em Roraima. A informação é da Assessoria de Comunicação do Governo do Estado.

Conforme o governo, o material produzido pelas secretarias é guardado no arquivo morto de cada órgão. A divisão de Patrimônio Histórico, localizada na avenida Jaime Brasil, possui arquivo de jornais e dados históricos sobre Roraima, com fotografias, discos (vinil e CD), além de livros que servem como fonte de pesquisa.

Segundo a chefe da Divisão do Patrimônio Histórico, Meire Saraiva, nenhuma secretaria encaminha documentos para o setor [...]. (HISTORIADORES..., 2008).

Além disso, o professor Jaci Guilherme Vieira faz uma crítica ao papel do estado para a preservação documental:

Segundo o professor, é responsabilidade do Governo do Estado criar esse acervo [público], que deve armazenar todos os documentos produzidos pela burocracia além de jornais e livros que vão servir para que futuros historiadores possam contar a história do Estado. (RORAIMA..., 2008).

Diante do contexto exposto, reconhecemos a necessidade de identificar, de forma mais concreta, a situação real de nossos acervos. Nesse sentido, selecionamos instituições de Boa Vista (ver Quadro 1) que se caracterizam por apresentarem documentos que são referências para os pesquisadores do estado. Das sete instituições consultadas, seis são públicas e apenas uma é de caráter privado.

QUADRO 01 - Centros de documentação de Boa Vista: caracterização e localização

\begin{tabular}{|l|l|l|}
\hline $\begin{array}{l}\text { Centros de documentação de } \\
\text { Boa Vista }\end{array}$ & Caracterização & $\begin{array}{l}\text { Localização, endereço e horário de } \\
\text { funcionamento }\end{array}$ \\
\hline Arquivo da Diocese de Roraima & Privado & $\begin{array}{l}\text { Prelazia de Roraima } \\
\text { Rua Bento Brasil, n } 613 \text { - Centro, Boa Vista/RR }\end{array}$ \\
\hline
\end{tabular}




\begin{tabular}{|c|c|c|}
\hline & & $\begin{array}{l}\text { (horário sujeito à disponibilidade do responsável pelo } \\
\text { arquivo e com prévia autorização) }\end{array}$ \\
\hline $\begin{array}{l}\text { Arquivo da Fundação Nacional do } \\
\text { Índio (FUNAI) }\end{array}$ & Público & $\begin{array}{l}\text { Sede da FUNAI } \\
\text { Rua Bento Brasil, n 536-E - Centro, Boa Vista/RR } \\
\text { (seg/sex: 8h-12h; 14h-18h) }\end{array}$ \\
\hline $\begin{array}{l}\text { Centro de Documentação } \\
\text { (CEDOC) do Núcleo Insikiran de } \\
\text { Formação Indígena da } \\
\text { Universidade Federal de Roraima } \\
\text { (UFRR) }\end{array}$ & Público & $\begin{array}{l}\text { UFRR } \\
\text { Campus do Paricarana - Av. Ene Garcez, no 2.413, } \\
\text { Bloco do Insikiran - Aeroporto, Boa Vista/RR } \\
\text { (seg/sex: 8h-12h; 14h-18h) }\end{array}$ \\
\hline Biblioteca Pública do Estado & Público & $\begin{array}{l}\text { Palácio da Cultura Nenê Macaggi } \\
\text { Praça do Centro Cívico, no } 84 \text {, pav. térreo - Centro, } \\
\text { Boa Vista/RR } \\
\text { (seg/sex: } 8 \mathrm{~h}-21 \mathrm{~h} \text { ) }\end{array}$ \\
\hline $\begin{array}{l}\text { Centro de Informação Ambiental, } \\
\text { Científica e Tecnológica (CIACT) } \\
\text { e reserva técnica do Museu } \\
\text { Integrado de Roraima (MIRR) }\end{array}$ & Público & $\begin{array}{l}\text { Museu Integrado de Roraima } \\
\text { Av. Brigadeiro Eduardo Gomes, no } 2.868 \text { - Parque } \\
\text { Anauá - Bairro dos Estados, Boa Vista/RR } \\
\text { (seg/sex: } 13 \mathrm{~h} 30-18 \mathrm{~h} \text { ) }\end{array}$ \\
\hline $\begin{array}{l}\text { Laboratório de Análise } \\
\text { Documental do Departamento de } \\
\text { História da Universidade Federal } \\
\text { de Roraima (UFRR) }\end{array}$ & Público & $\begin{array}{l}\text { UFRR } \\
\text { Campus do Paricarana - Av. Ene Garcez, no 2.413-, } \\
\text { Bloco I - Aeroporto, Boa Vista/RR } \\
\text { (seg/sex: 14h-18h) }\end{array}$ \\
\hline $\begin{array}{l}\text { Núcleo de Documentação } \\
\text { Histórica do Estado da Divisão de } \\
\text { Patrimônio Histórico do Estado }\end{array}$ & Público & $\begin{array}{l}\text { Casa da Cultura Madre Leotávia Zoller } \\
\text { Rua Jaime Brasil, no } 235 \text { - Centro, Boa Vista/RR } \\
\text { (seg/sex: 7h30-18h) }\end{array}$ \\
\hline
\end{tabular}

Fonte: Dados recolhidos na atividade de campo da pesquisa "Diagnóstico e Cadastramento do Acervo Documental dos Centros de Informação de Boa Vista/RR".

Após um contato prévio com as instituições, iniciamos o diagnóstico dos centros de documentação, tomando como premissas as regras básicas de conservação documental (acondicionamento, armazenamento, conservação e restauração), segurança e gestão de acervos (BACELLAR, 2005, p. 57).

Para mensurar as variáveis do nosso estudo e obter uma gama maior de informações sobre as instituições, que se complementaram à nossa observação in loco, elaboramos um questionário com 38 perguntas objetivas e semifechadas, intitulado "Questionário sobre segurança, acondicionamento do acervo e condições físicas e materiais dos Centros de Documentação de Boa Vista/RR". A elaboração tomou como exemplo o modelo formulado pelo Museu de Astronomia e Ciências 
Afins e pelo Museu Villa-Lobos na construção de uma política de segurança para arquivos, bibliotecas e museus (MUSEU de Astronomia e Ciências Afins, 2006, p. 105). A fim de adaptá-lo à realidade dos nossos acervos e às informações que desejávamos recolher em nossa pesquisa, realizamos algumas modificações (acréscimos e supressões). Por último, o questionário foi dividido em seis seções: dados gerais, infra-estrutura, segurança, instalações do centro de documentação, mecanismos de controle de acesso e sistemas de proteção do acervo (PAES, 2005, p. 35-36).

As seis instituições que responderam ao questionário até a data-limite (14 de abril de 2009), correspondentes a $85,71 \%$ do total, foram: Diocese de Roraima, Biblioteca Pública do Estado, Museu Integrado de Roraima, Núcleo Insikiran de Formação Superior Indígena da UFRR, Departamento de História da UFRR e Divisão de Patrimônio Histórico do Estado.

A análise dos dados demonstrou a realidade e a conjuntura das pesquisas e centros de informação em Roraima.

Constatamos que a maioria das instituições não possui uma área adequada para a consulta das fontes documentais que garanta a segurança do acervo e o conforto do pesquisador. Pois, a organização do espaço físico não conjuga fatores essenciais como iluminação, climatização do ambiente e mobiliário.

GRÁFICO 01 - Ciência dos riscos aos quais o acervo está sujeito e registro de perdas nos últimos 10 anos

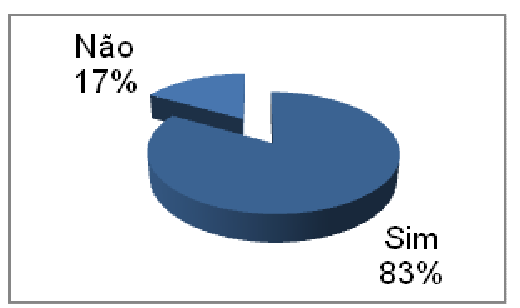

Fonte: Informações do Questionário aplicado junto aos Centros de Documentação de Boa Vista

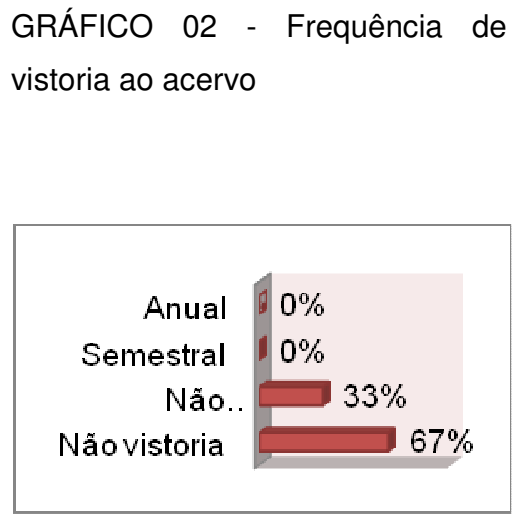
Fonte: Informações do Questionário aplicado junto aos Centros de Documentação de Boa Vista
GRÁFICO $03 \quad$ - Instalações construídas para a finalidade de abrigar o acervo

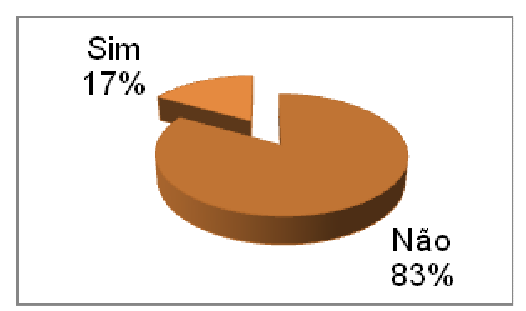

Fonte: Informações do Questionário aplicado junto aos Centros de Documentação de Boa Vista 
De maneira geral, os centros de informação não possuem profissionais especializados que possam atender satisfatoriamente e acompanhar o usuário em sua pesquisa, visto que não há uma política de formação e capacitação de recursos humanos nas áreas de museologia, biblioteconomia e/ou arquivologia:

No estado, devido a falta de curso superior em biblioteconomia, há poucos profissionais da área que atuam em escolas, faculdades e universidades. Todos os responsáveis pelo funcionamento das bibliotecas têm formação na área fora de Roraima.

[...] Para os profissionais da informação, dentre eles o bibliotecário, o objetivo de trabalho é a informação, devendo este estar envolvido em todo o ciclo documental ou informacional. A informação é o ponto principal para atuação do profissional bibliotecário, por isso a importância de ser formado e estar sempre se qualificando dentro da área. (LIMA, 2009).

A equipe que trabalha na maior parte destes centros é pequena, como pode ser demonstrado no Gráfico 4. No entanto, verificamos esforços dessas pessoas para contornar as dificuldades no tratamento documental e no atendimento ao público.

GRÁFICO 04 - Número de pessoas trabalhando no centro de documentação

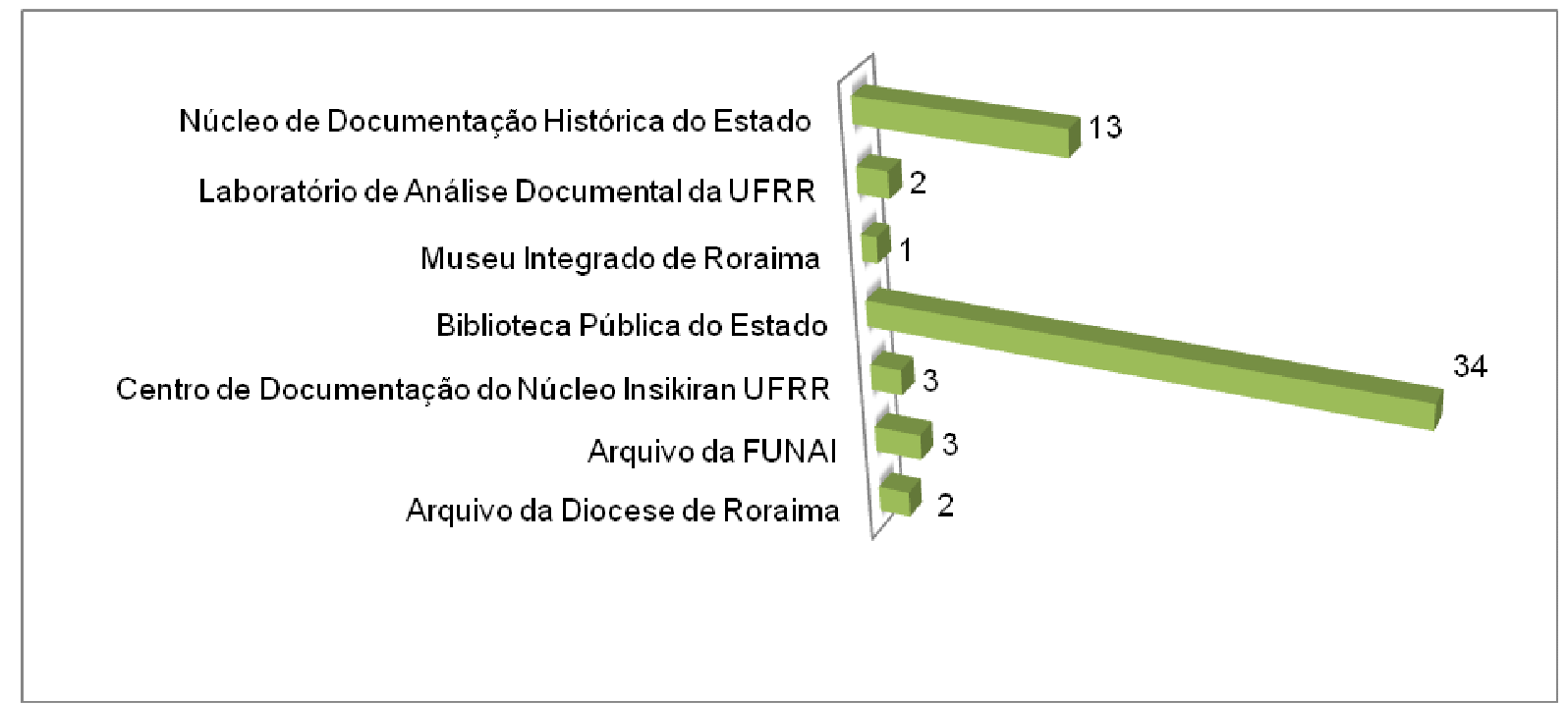

Fonte: Informações do Questionário aplicado junto aos Centros de Documentação de Boa Vista

As instalações são inapropriadas para a guarda do acervo, já que não se tratam de edifícios planejados para essa finalidade. Grande parte dos prédios não é provida de equipamentos de segurança (alarmes, extintores de incêndio, circuito interno de TV, 
sistema de detecção eletrônica) e mecanismos de controle ambiental (aparelhos de ar condicionado, desumidificadores, iluminação artificial adequada etc.).

GRÁFICO 05 - Equipamentos dos centros de documentação

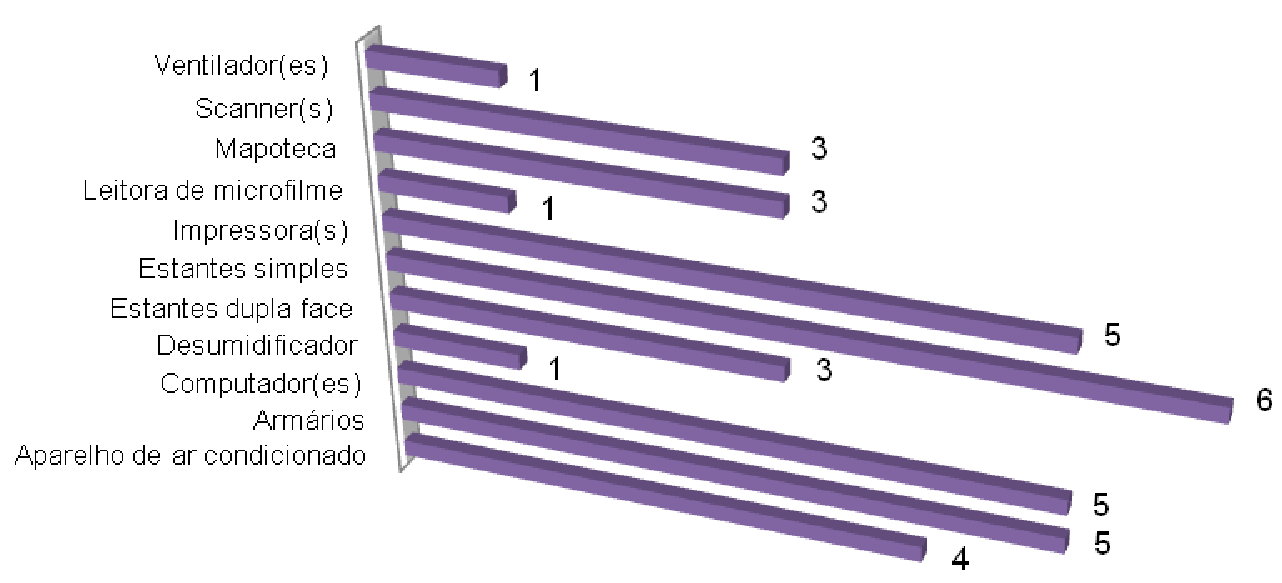

Fonte: Informações do Questionário aplicado junto aos Centros de Documentação de Boa Vista

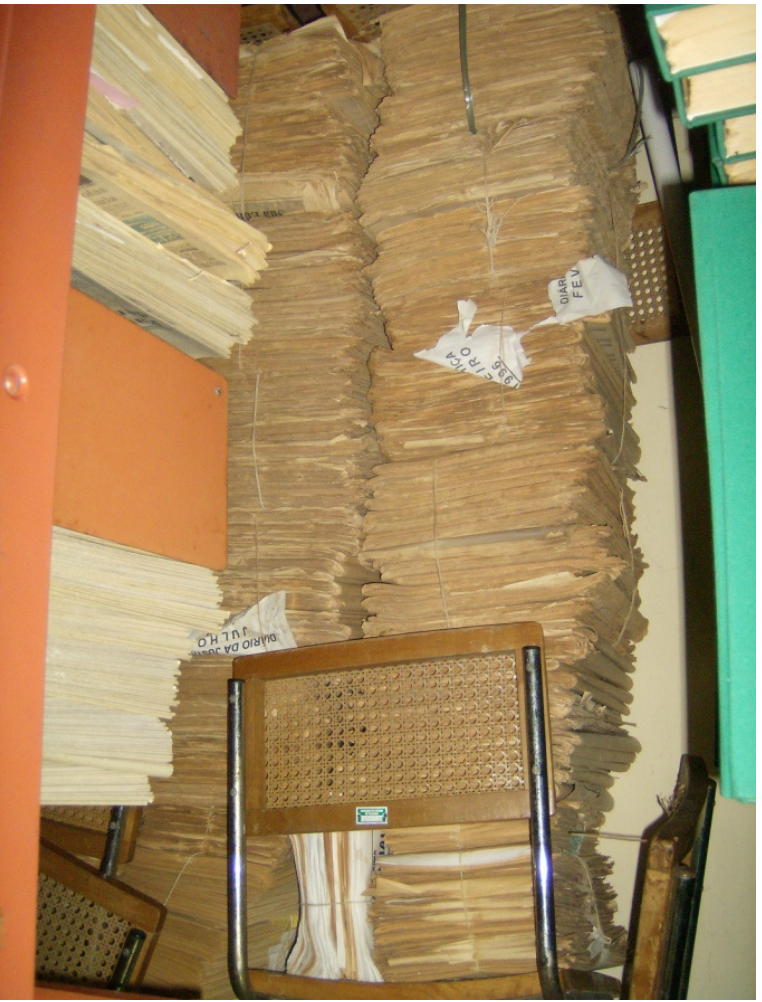

FIGURA 01 - Casa da Cultura. Mau

acondicionamento de jornais. Fonte: IPHAN/SubRegional de Roraima. Fotografia de Carla Moraes (abril/2009).

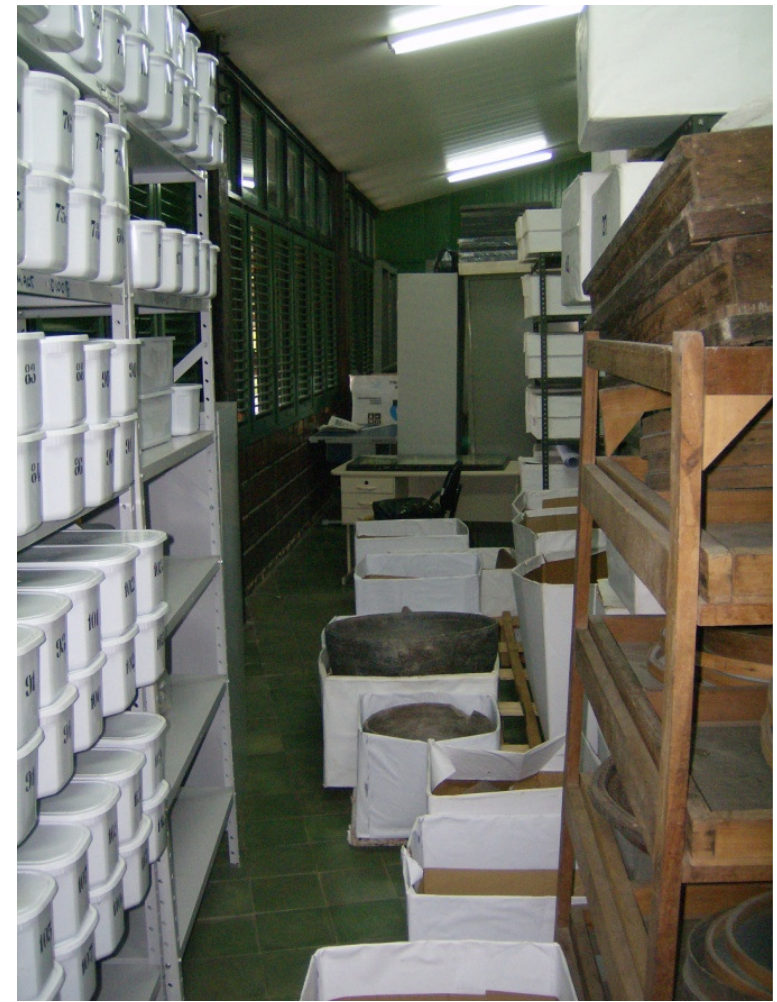

FIGURA 02 - Reserva técnica do Museu

Integrado de Roraima. Falta de espaço para o acervo.Fonte: IPHAN/Sub-Regional de Roraima. Fotografia de Carla Moraes (abril/2009). 


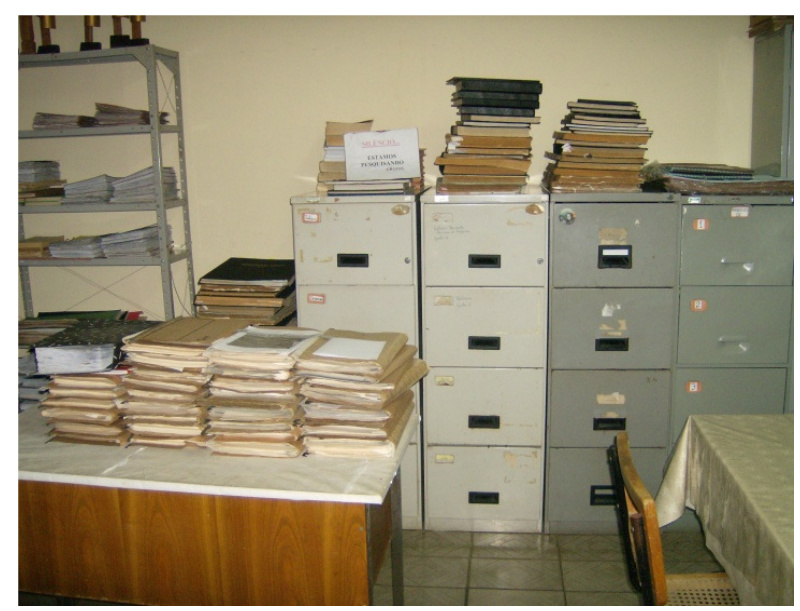

FIGURA 03 - Casa da Cultura. Falta de espaço para documentos. Fonte: IPHAN/Sub-Regional de Roraima. Fotografia de Carla Moraes (abril/2009)

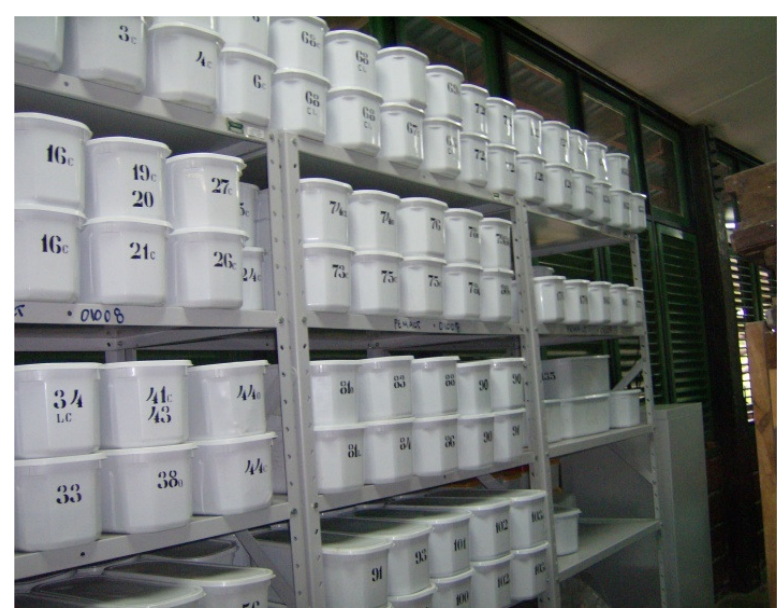

FIGURA 04 - Reserva técnica do Museu Integrado de Roraima. Material arqueológico em caixas de sorvete. Fonte: IPHAN/SubRegional de Roraima. Fotografia de Carla Moraes (abril/2009).

Entre as principais ameaças ao acervo, foram citadas pelos entrevistados: umidade, alta temperatura, instalações inadequadas, incidência solar, falta de espaço para a documentação, fungos, mofo e cupins.

GRÁFICO 06 - Principais ameaças ao acervo documental

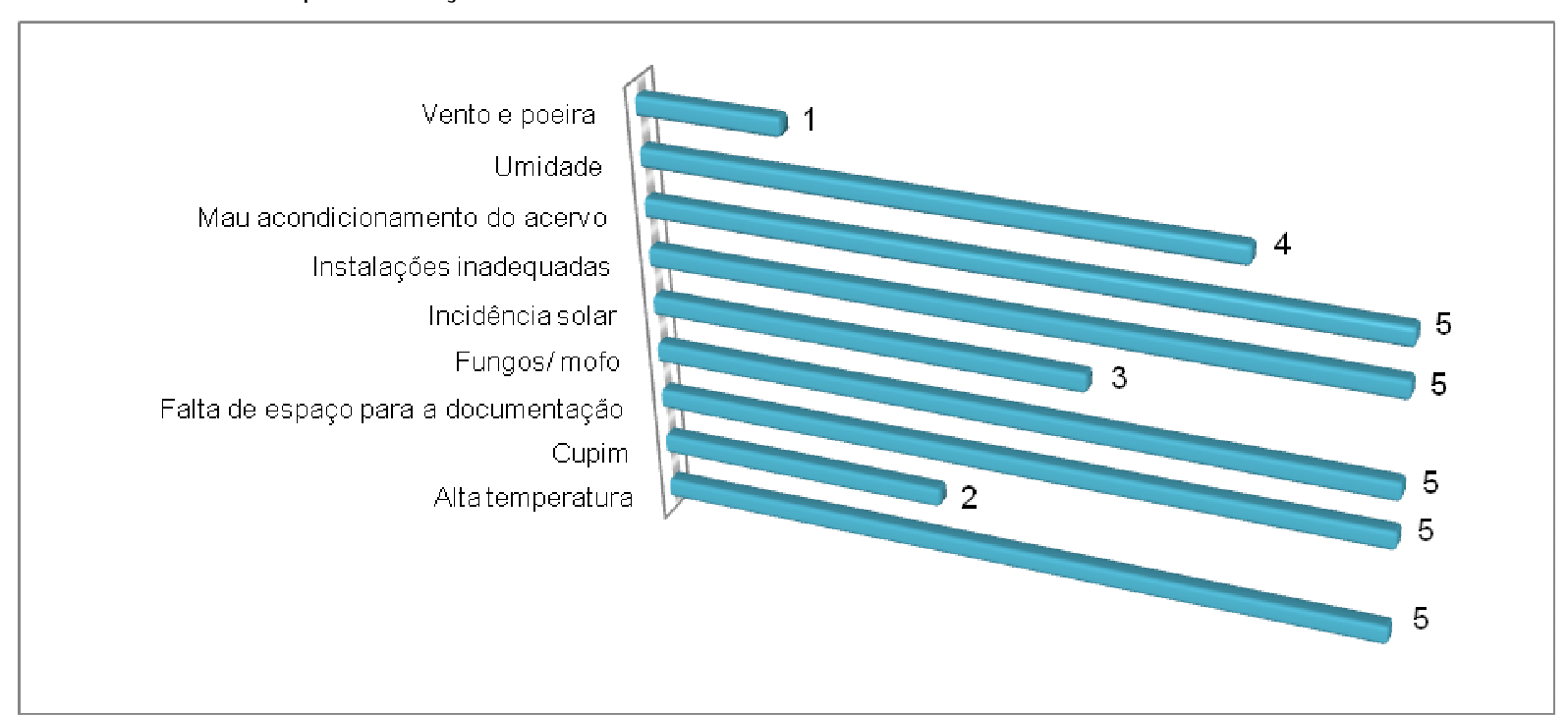

Fonte: Informações do Questionário aplicado junto aos Centros de Documentação de Boa Vista

Apesar disso, nenhum dos centros de informação possui um plano para salvar o acervo em caso de emergência, embora a maioria tenha registrado perdas 
relevantes de documentos nos últimos 10 anos. Estas instituições não possuem um programa de conservação preventiva e apenas uma afirmou ter recursos destinados à conservação e restauração do acervo.
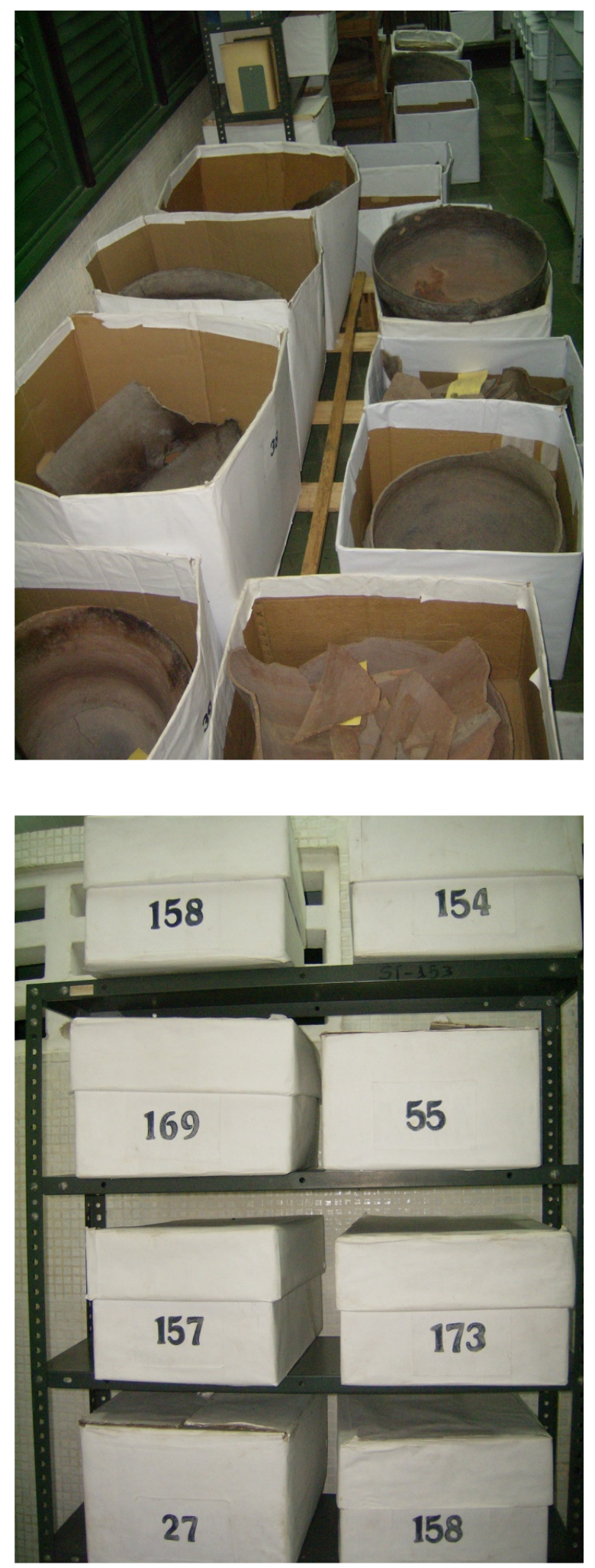

FIGURA 05 - Reserva técnica do Museu Integrado de Roraima. Urnas funerárias em caixas de papelão. Fonte: IPHAN/Sub-Regional de Roraima. Fotografia de Carla Moraes (abril/2009).
FIGURA 06 - Reserva técnica do Museu Integrado de Roraima. Material arqueológico em caixas de papelão. Fonte: IPHAN/Sub-Regional de Roraima. Fotografia de Carla Moraes (abril/2009). 


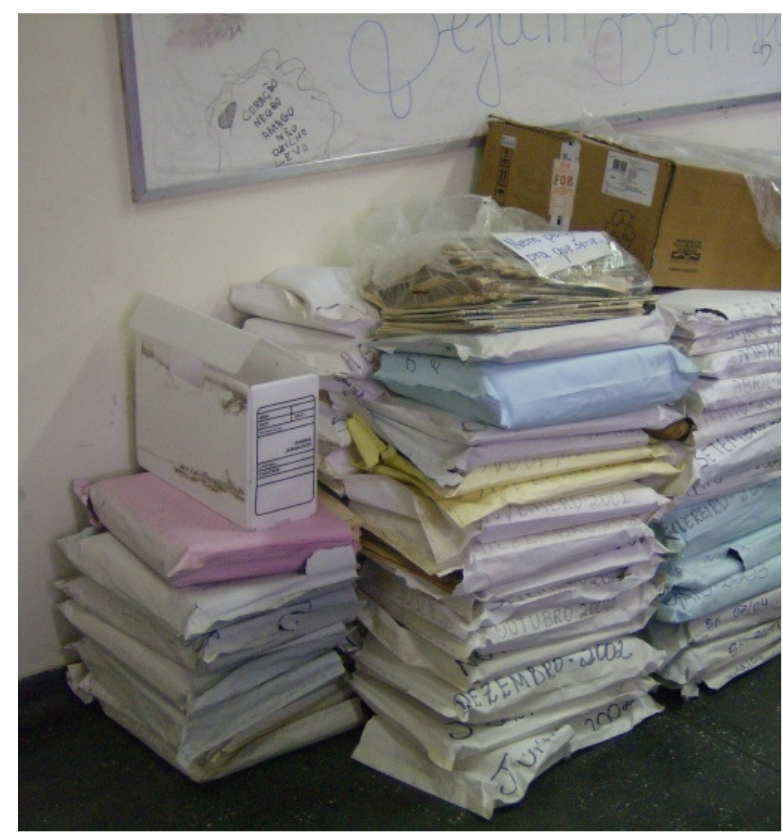

FIGURA 07 - Laboratório de Análise Documental da UFRR. Jornais empilhados sobre o chão. Fonte: IPHAN/Sub-Regional de Roraima.

Fotografia de Carla Moraes (abril/2009).

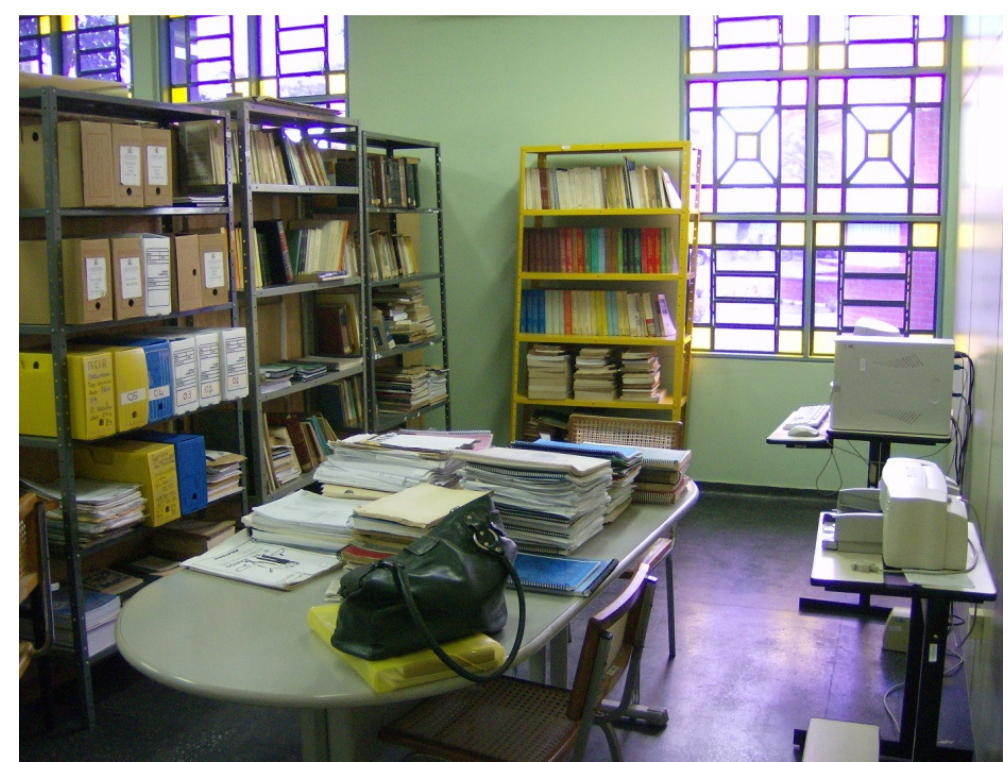

FIGURA 08 - Laboratório de Análise Documental da UFRR. Incidência solar sobre o acervo e espaço de consulta inadequado Fonte: IPHAN/Sub-Regional de Roraima. Fotografia de Carla Moraes (abril/2009).

No que concerne aos instrumentos para processamento técnico do acervo, as instituições usam, em sua maioria, livros de registro ou simples listagens para controle dos documentos. Dentre elas, apenas três estão em processo de informatização sumária de seu acervo. A construção da base de dados digital, em razão do volume e diversidade documental, será lenta, mas extremamente necessária.

Esse significativo acervo perfaz um total de cerca de 65.000 documentos nas seis instituições. Porém, não existem investimentos sólidos no seu incremento. Somente três centros de informação afirmaram realizar frequentes aquisições. 
O quadro diagnosticado revela, portanto, um panorama alarmante, confirmando algumas afirmações explicitadas por usuários desses centros de informação, como Vieira:

$\mathrm{Na}$ avaliação do professor do curso de História da UFRR, Jaci Guilherme Vieira, Roraima é o único Estado que não tem arquivo público nos moldes dos demais estados [...]. Conforme Guilherme, os locais não têm estrutura para pesquisa, nem pessoal qualificado para trabalhar no setor, como por exemplo, historiadores, pesquisadores e arquivistas [...]. Guilherme salienta que pesquisar sobre a história local é difícil porque não há material suficiente e normalmente os pesquisadores buscam informações em outros estados. 'Não se tem acesso. Caso seja necessário saber sobre a época da ditadura em Roraima, ficamos sem informações', reclamou. (HISTORIADORES..., 2008, grifo nosso).

A Divisão de Patrimônio Histórico, referência mais lembrada quando se fala em documentação histórica de Roraima, também não possui condições estruturais para a guarda e conservação dos documentos:

É nesse espaço que a Profa Meire Saraiva, uma grande batalhadora e guardiã dos documentos que compõe o acervo da Casa da Cultura, juntamente com o Terêncio Lima e o Nereu Souto Maior, atendem pessoalmente os alunos que buscam informações sobre Roraima. $O$ atendimento é realizado para todos os níveis, desde o aluno de $1^{\circ}$ e $2^{\circ}$ graus até o aluno universitário, é lá que conseguimos as parcas informações sobre a história de Roraima e é na Divisão de Patrimônio Histórico que estão os poucos documentos que formam a memória do povo de Roraima.

No entanto, quem tiver a intenção de utilizar esses serviços tem agora que suportar um calor medonho e a falta de espaço para os servidores e visitantes, já que as instalações da Divisão de Patrimônio Histórico hoje se resumem ao anexo. (MULINARI, 2007).

O Centro de Informação Ambiental, Científica e Tecnológica e a reserva técnica funcionam nas instalações do Museu Integrado de Roraima, compartilhando os mesmos problemas:

Além da sujeira, os boa-vistenses também reclamam do abandono do Museu. O local que possui sua arquitetura em madeira está repleto de cupins, e segundo os usuários os objetos de exposição estão mal cuidados. O estudante, Felipe Aguiar, expõe que 0 ano passado, a aranha caranguejeira, um dos acervos de animais, havia fugido. 'Não apenas a falta de cuidado, mas o espaço não tem atrativo, não possui uma boa aparência e métodos didáticos. Ainda querem chamar de museu, o local tem 22 anos e nunca foi valorizado', reclama. (CHACON, 2009). 
O museu que deveria estar aberto ao público, se encontra fechado, com suas toras de madeira, que sustentam parte do telhado, corroídas pelos cupins, aumentando os riscos de ceder e causar maiores danos. (CAVINATO, 2009).

No decorrer da pesquisa, a difícil situação dos centros de documentação de Boa Vista foi se cristalizando, demonstrando as inúmeras barreiras que existem para a conservação dos acervos. Há uma deficiência muito grande, que vai desde as questões mais simples, como a falta de material de escritório, mobiliário e equipamentos específicos, até problemas mais complexos, como instalações totalmente inadequadas e carência de pessoal graduado nas áreas de Biblioteconomia e Arquivologia. A partir desse diagnóstico, apresentamos algumas reflexões que podem contribuir para o planejamento e ações que visem à segurança e conservação dos acervos pesquisados.

\section{Considerações finais}

Os principais acervos documentais sobre Roraima não se encontram organizados, gerando dificuldades de acesso ao público externo, que se depara com uma grande diversidade de documentos (livros, revistas, jornais, relatórios, fotografias etc.) sem prévia catalogação. Como encontrar, em meio a caixas, estantes e armários repletos de papéis, o documento que nos interessa de fato?

Esta primeira constatação nos leva a outras implicações. Tendo em vista que ainda não foi instituída a prática de quantificar e classificar a documentação, não é possível precisar, na maioria dos centros de informação, o volume do acervo. Como saber quantos e quais são os documentos sobre Roraima em cada um desses lugares? Essa estimativa é, hoje, impossível, tornando o trabalho dos pesquisadores mais árduo e dificultando medidas de preservação e segurança. No entanto, a importância desses centros é inquestionável, tendo em vista que esses são os principais locais onde é possível consultar documentos históricos do estado.

Outro problema é proporcionado pela restrição de acesso aos documentos. Alguns acervos não estão totalmente disponíveis para os pesquisadores, ora pela existência 
de documentos sigilosos, ora por limitações de horário para a consulta da bibliografia e, por fim, por proibições à reprodução do material.

Há, ainda, a constatação de que uma série de fontes essenciais ao entendimento do processo formador da história, cultura e sociedade roraimenses encontra-se nas mãos de particulares, que não as disponibilizam. A inacessibilidade dessas "relíquias de família", patrimônio de todos, impede o levantamento das condições dessas coleções. Por outro lado, muitos pesquisadores localizam e acessam documentos raros, mas não divulgam sua origem aos demais estudiosos e ao público em geral. Esta prática corrente entre professores e estudantes dificulta o acesso às fontes primárias e restringe as possibilidades de novas pesquisas que precisem revisitar evidências fundamentais sobre o estado.

O diagnóstico também tornou mais explícito o fato de que importantes fontes históricas não se encontram em Roraima, mas em arquivos, bibliotecas e museus de outros estados e países. Infelizmente, se quiséssemos solicitar o direito de posse sobre esta documentação, nossos centros de informação não apresentariam as condições ideais de acondicionamento, deixando-nos numa desconfortável situação, um verdadeiro impasse. Como reivindicar para Roraima estes documentos se não temos espaço, condições e pessoal especializado para organizar, conservar, manusear e disponibilizar esse acervo ao público?

Esses problemas citados são, a nosso ver, alguns dos maiores entraves ao desenvolvimento de pesquisas em Roraima. Nessa conjuntura, nosso estudo pretende ser um alerta ao público para o atual estado físico e as condições de manutenção e divulgação dos acervos documentais.

Acreditamos, assim, que é preciso haver uma mobilização de pesquisadores, professores, estudantes e agentes públicos responsáveis, a fim de reconhecer a importância de nossos centros de documentação. Precisamos, portanto, enriquecer nossos acervos, realizando pesquisas, fortalecendo e legitimando o papel das instituições que detêm a guarda dos documentos estaduais. E mais, um grande investimento, com o incremento da infra estrutura, é necessário à organização, conservação e, sobretudo, divulgação das fontes. 
A disseminação da documentação, sob a consciência de que ela é um bem coletivo, é fundamental para que os centros de informação cumpram o seu papel social que inclui, entre outros fatores, estabelecer subsídios para políticas culturais mais sólidas. Ao mesmo tempo, estimular o público a visitar os centros de pesquisa e documentação é uma condição sine qua non para a valorização do nosso patrimônio cultural.

\section{Nota}

(1) Uma solução alternativa para o controle da umidade é o uso de sílica-gel em recipientes plásticos, nos equipamentos que guardam os documentos (PAES, 2004, p. 141).

\section{Referências bibliográficas}

BACELLAR, Carlos. Uso e mau uso dos arquivos. In: PINSKI, Carla Bassanezi. (Org.). Fontes históricas. São Paulo: Contexto, 2005. p. 23-79.

BELLOTO, Heloisa Liberalli. Arquivos permanentes: tratamento documental. 2. ed. rev. e ampl. Rio de Janeiro: FGV, 2004.

BELLOTO, Heloisa Liberalli. Arquivos permanentes: tratamento documental. 2. ed. rev. e ampl. Rio de Janeiro: FGV, 2004. Resenha de: FUNARI, Pedro Paulo A. Revista CPC eletrônica, São Paulo, v. 1, n. 2, p. 129-132, maio/out. 2006.

BRASIL. Decreto-Lei no. 25, de 30 de novembro de 1937. In: Coletânea de leis sobre preservação do patrimônio. Rio de Janeiro: IPHAN, 2006. p. 99-107.

BRASIL. Lei no. 8.159, de 8 de janeiro de 1991. Diário Oficial da União, Poder Executivo, Brasília, DF, 9 jan. 1991. (pub. ret. em 28 jan. 1991).

CALDEIRA, Cleide Cristina. Conservação preventiva: histórico. Revista CPC eletrônica. São Paulo, v. 1, n. 1, p. 91-102, nov. 2005/ abr. 2006. Disponível em: http://www.usp.br/cpc/.

CAVINATO, Maria Augusta. Parque Anauá: descaso e destruição são hoje as atrações. Jornal Folha de Boa Vista, abr. 2009. Disponível em: <http://www.folhabv.com.br/fbv/noticia.php?id=59737>. Acesso em: 15 abr. 2009 .

CHACON, Sonja. Usuários afirmam que Parque Anauá está abandonado. Jornal Folha de Boa Vista, jan. 2009. Disponível em: <http://www.folhabv.com.br/fbv/noticia.php?id=53505>. Acesso em: 15 abr. 2009.

HISTORIADORES debatem arquivo público. Jornal Folha de Boa Vista. Boa Vista, maio 2008. Disponível em: <http://www.folhabv.com.br/fbv/noticia.php?id=39614>. Acesso em: 29 mar. 2009. 
LIMA, Vanessa. Profissionais da área de Biblioteconomia são poucos em RR. Jornal Folha de Boa Vista, mar. 2009. Disponível em: <http://www.folhabv.com.br/fbv/noticia.php?id=57732>. Acesso em: 15 abr. 2009.

MULINARI, Selma. Casa da Cultura Madre Leotávia Zoller II. Jornal Folha de Boa Vista. Boa Vista, nov. 2007. Disponível em: <http://www.folhabv.com.br/fbv/noticia.php?id=31711>. Acesso em: 30 mar. 2009.

MUSEU de Astronomia e Ciências Afins (MAST). Conservação de acervos. Rio de Janeiro: MAST, 2007.

MUSEU de Astronomia e Ciências Afins (MAST). Política de segurança para bibliotecas, arquivos e museus. Rio de Janeiro: MAST, 2006.

PAES, Marilena Leite. Arquivo: teoria e prática. 3. ed. rev. ampl. reimp. Rio de Janeiro: FGV, 2004.

RORAIMA é o único estado que não tem um arquivo público. Jornal Folha de Boa Vista, Boa Vista, abr. 2008. Disponível em: <http://www.folhabv.com.br/fbv/noticia.php?id=39161>. Acesso em: 30 mar. 2009.

SILVA, Zélia Lopes da. (Org.). Arquivos, patrimônio e memória: trajetórias e perspectivas. São Paulo: UNESP/FAPESP, 1999. (Seminários e debates).

\section{Crédito}

* Graduada em Arquitetura e Urbanismo pela Universidade Federal da Paraíba (UFPB) e Mestre em Desenvolvimento Urbano pela Universidade Federal de Pernambuco (UFPE)

Técnica do Instituto do Patrimônio Histórico e Artístico Nacional (IPHAN)

e-mail: carla gi@hotmail.com

** Licenciada Plena em História pela Universidade Federal de Roraima (UFRR) e Especializanda em Patrimônio pelo Instituto do Patrimônio Histórico e Artístico Nacional (IPHAN)

e-mail: paulinaramalho@yahoo.com.br

A pesquisadora Paulina Onofre Ramalho recebe Bolsa de pesquisa da Fundação Darcy Ribeiro (FUNDAR) e apoio do IPHAN para o desenvolvimento desta pesquisa no âmbito do Programa de Especialização em Patrimônio do IPHAN (PEP). 